\title{
Comparison of Velocity Distribution in the Boundary Layer between Ship and Model
}

\author{
By Kaname Taniguchi*, Member \\ Takashi Fujita**, Member
}

\begin{abstract}
Summary
Comparative tests on the velocity distribution in boundary layer were carried out on a large tanker and her 6.25 meter model.

Measurements were made at a point about $0.1 \mathrm{Lpp}$ forward of A.P. and $0.3 \times$ (design draft), above base line. Velocity distribution in boundary layer on the ship agrees approximately with the $1 / 7$ th power law. Profile of velocity distribution on the model shows more remarkable drop. near the hull surface than that of the ship and is very close to separation. Considerable difference in flow direction in the boundary layer can be seen between on ship and model.
\end{abstract}

\section{Introduction}

In accordance with the recent remarkable growth in ship dimensions and fullness, problems of scale effect on wake have become one of the most important problems with regard to the estimation of propulsive performance, propeller design and propeller induced vibrations.

Besides, with the increasing fullness the unstable phenomenon has been sometimes observed in the self-propulsion tests of full ship models. And the question has been raised on the study of ship-model correlation whether such an unstable phenomenon exists on an actual ship as well.

Although there are many theoretical and experimental studies on the ship-model correlation, there is quite few information of the full scale wake measurement(1) (5), especially none of the recent large tankers. In order to contribute to this field of study, the authors carried out an experiment to measure the velocity distribution in the boundary layer on a large full tanker. Although the measurement was made at the only one point, it gives us a lot of valuables information.

After the ship experiment, model tests were carried out at quite similar conditions.

In the present paper, experimental techniques of full scale wake measurement as well as comparison of the test data on ship and model are described.

\section{Test procedures}

\subsection{Ship experiment}

This ship was a tanker of 160,000 DWT built in Nagasaki Shipyard. Particulars of the

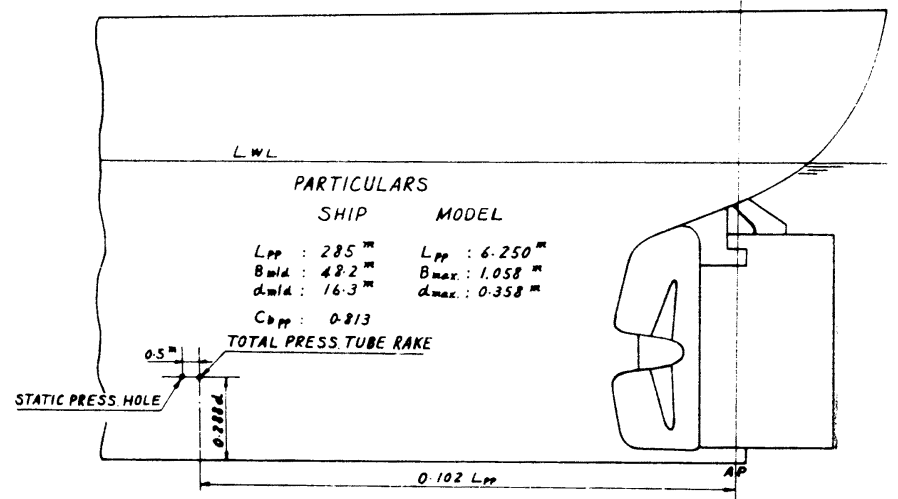

Fig. 1 Particulars of Ship \& Model, Position of Measuring Point

* Manager, Nagasaki Technical Institute, Mitsubishi Heavy Industries, Ltd.

** Experimental Tank, Nagasaki Technical Institute, Mitsubishi Heavy Industries, Ltd. 


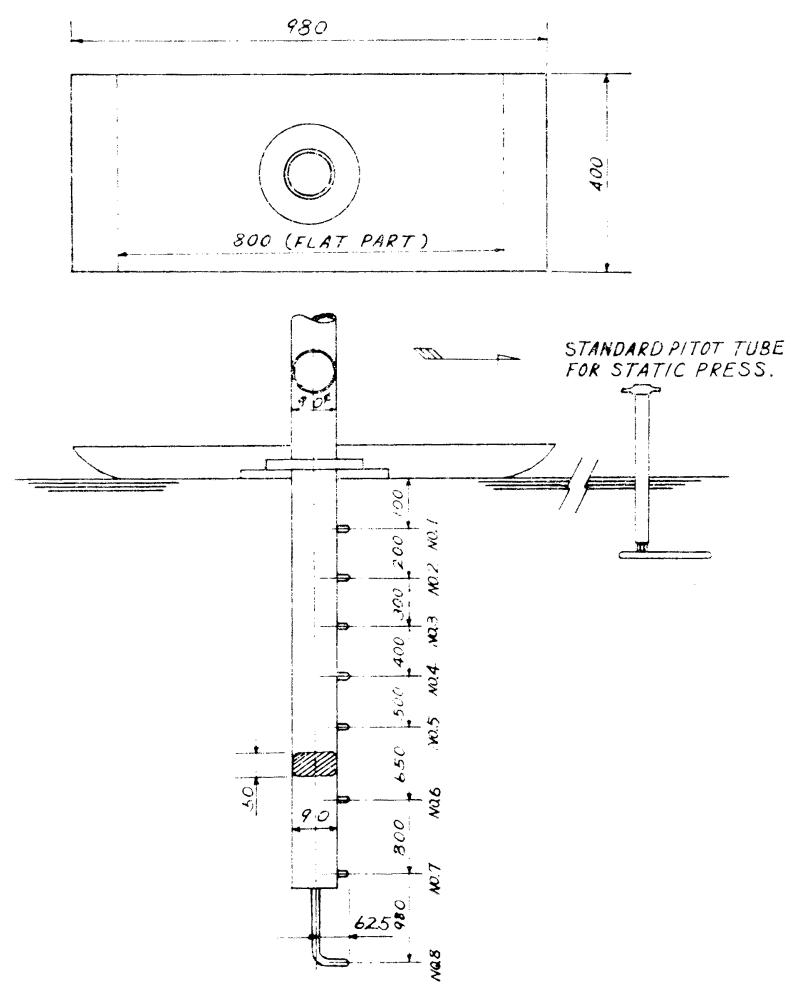

Fig. 2 Total Pressure Tube and End Plate for Calibration

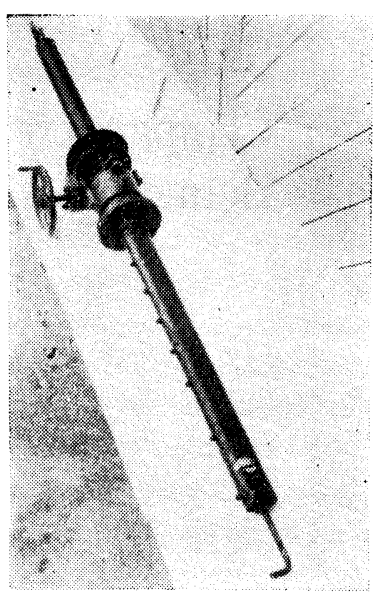

Fig. 3 Total Pressure Tube Rake for Ship Experiment

ship and model and the positition of measuring point are shown in Fig. 1.

As well known, velocity of flow can ke calculated from the dynamic pressure which is obtained from the difference between the total and the static pressure at the measuring point.

It is comparatively easy to measure the total pressure, but rather difficult to measure

he static pressure in three dimensional flow such as around the ship's hull.

On the present ship experiment, the total pressure was measured by the total pressure tube rake which is shown in Figs. $2 \sim 5$. The rake has eight total pressure tubes and they are arranged at 100 , $200,300,400,500,650,800$ and $980 \mathrm{~mm}$ apart from the hull surface. The static pressure at each total pressure tube was represented by the static pressure on the hull surface. It was measured at the static pressure hole which was arranged on the hull surface $500 \mathrm{~mm}$ forward from the total pressure tube rake and on the same water line as shown in Fig. 1. The total pressure tube rake was set normally to the hull surface.

In order to measure the total pressure and flow direction as accurate as possible, the total pressure tube rake is fitted with a device to turn itself around its center axis and to change the setting angle of total pressure tubes against the flow direction. By means of this device we can easily fix an

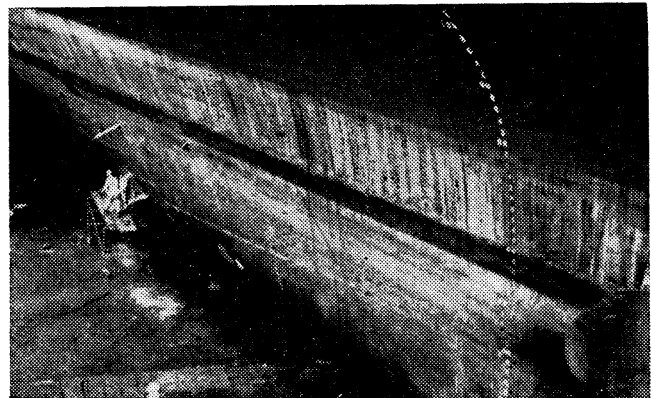

Fig. 4 Total Pressure Tube Rake fitted to Ship

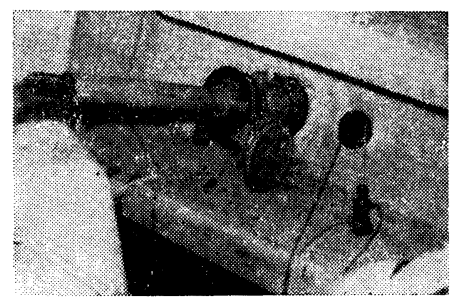

Fig. 5 Total Pressure Tube fitted to Ship (inside of Ship) 


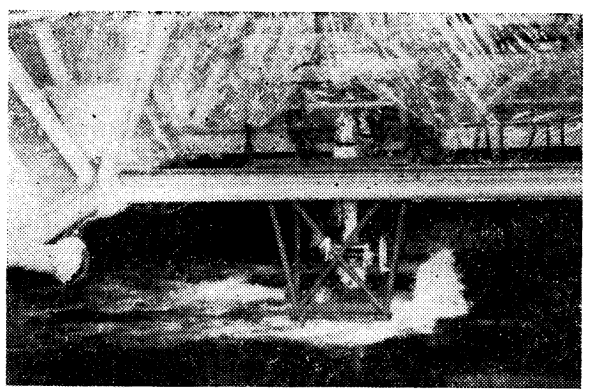

Fig. 6 Calibration of Total Pressure Tube Rake in the Towing Tank
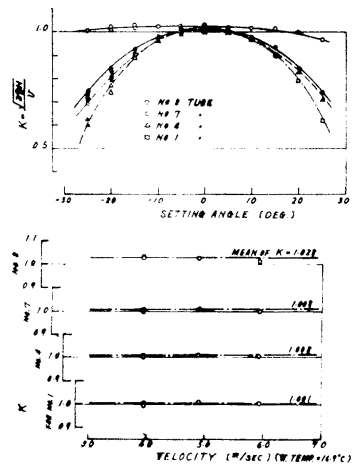

Fig. 7 Results of Calibration for Total Pressure Tube

arbitrary setting angle and read it on a manometer board set inside of the ship.

The measurements were carried out during the ship's trial runs, both of fully loaded and ballasted condition. Sea condition was very smooth at fully loaded trial, but sea state was moderate at ballasted trial. The water temperature was $22^{\circ} \mathrm{C}$ for both conditions.

Setting angles of the total pressure tube were changed several times during each trial run over the measured mile and the pressures of all tubes were measured at each setting angle.

Transparent plastic tubes were used to connect each pressure tube to a mercury manometer.

On the ship experiment, especially at ballasted condition, there was considerable pressure fluctuation, so we used a damper made of blass tube to restrict the fluctuation of manometer reading.

The total pressure tube rake was calibrated in the experimental tank up to almost the same speed as the ship experiment. The calibration setup is shown in Fig. 6 by a photograph during the calibration. Fig. 7 is an example of the plottings of the calibration test. From the figure it can be seen that the calibration constant $K(=\sqrt{ } 2 g H / V)$ is sufficiently constant for the velocity and that the direction of flow is determined easily.

The measuring instrument were fitted on the ship during the ship was in dry dock as shown in Fig. 4 and 5 .

\subsection{Model test}

The model tests were carried out at the condition similar to the ship experiment. In the model tests the authors used the total pressure tube which was especially made as similar as possible to that used on the ship experiment. This total pressure tube was rotated around its axis to measure the direction of flow. Static pressure was also measured by static pressure hole at the similar position on the model hull.

The speeds on the model tests were chosen corresponding to the mean relative water speed of the ship trial runs of each loaded condition. The detailed measurements were carried out in self-propulsion condition as well as in towed condition to investigate the effect of propeller suction.

In addition to the above measurement the authors tried to use a five hole spherical pitot probe, which is $10 \mathrm{~mm}$ in diameter, to measure the velocity and direction of three dimensional flow at the measured position of model in towed condition.

All of these measuring instruments were also calibrated beforehand in the experimental tank. 


\section{Test Results}

\subsection{Velocity distribution and direction of flow}

Measured ship speed of each trial run was corrected for current. Plotting of non-dimensional value $V / V s$ on the basis of the setting angle of the total pressure tube rake is shown in Fig. 8 as an example for the fully loaded condition, where $V s$ is the corrected ship speed and $V$ is the velocity of flow calculated from the pressure difference between each total pressure and static pressure. In the figure, $V / V s$ of each total pressure tube changes against its setting angle, so the direction of flow is obtained from the setting angle corresponding to the maximum value of $V / V s$ and the true velocity of flow is obtained from the maximum value of $V / V s$.

On the fully loaded condition, the measurements were almost perfect, but on the ballasted condition, there were considerable discrepancies between the test results of up running and of down running, especially on the direction of flow near the hull surface. The principal cause of such discrepancies is thought to be in that the ship had a little drift angle on the trial runs because of side wind.

Model data of total pressure tubes were analyzed in the same way as the ship's data, also the authors obtained the direction and velocity of flow from the data of five hole spherical pitot probe.

Maximum values of $V / V s, V / V m$ and the direction of flow are plotted on the basis of

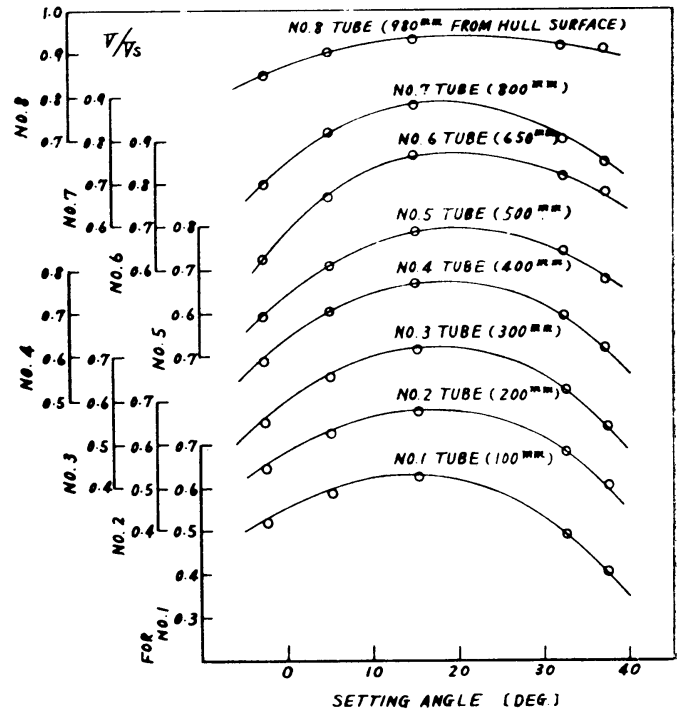

Fig. 8 Cross Curves of $V / V s$ $y /$ Lpp for both ship and model as shown in Fig. 9 and 10, where $V m$ is model speed and $y$ is the distance between the hull surface and the measured point. In the figure $V / V s$ and the direction of flow of ship experiment represent the average value of several measurements of trial runs on each loaded condition.

On the direction of flow, zero degree is taken parallel to the base line and the upward flow is taken positive.

Model data of total pressure tube plotted in Fig. 9 are for the test results of self-propulsion condition. The effect of propeller suction is shown in Fig. 11, where $\mathrm{TR}$ and TS condition means towing and self-

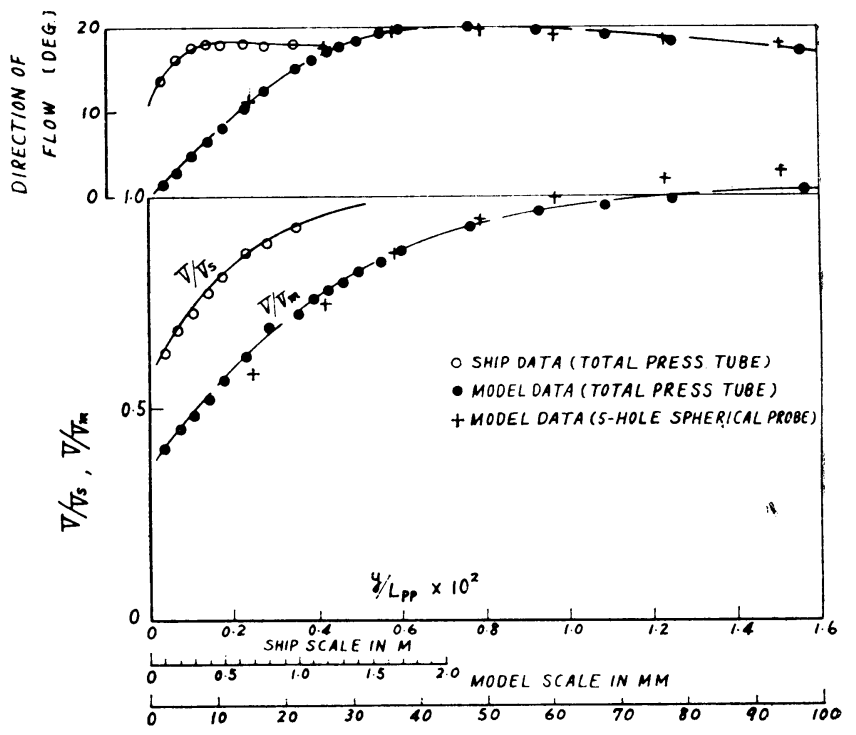

Fig. 9 Comparison of Velocity Distribution and Direction of Flow between on Ship \& Model (Fully Loaded Condition) 


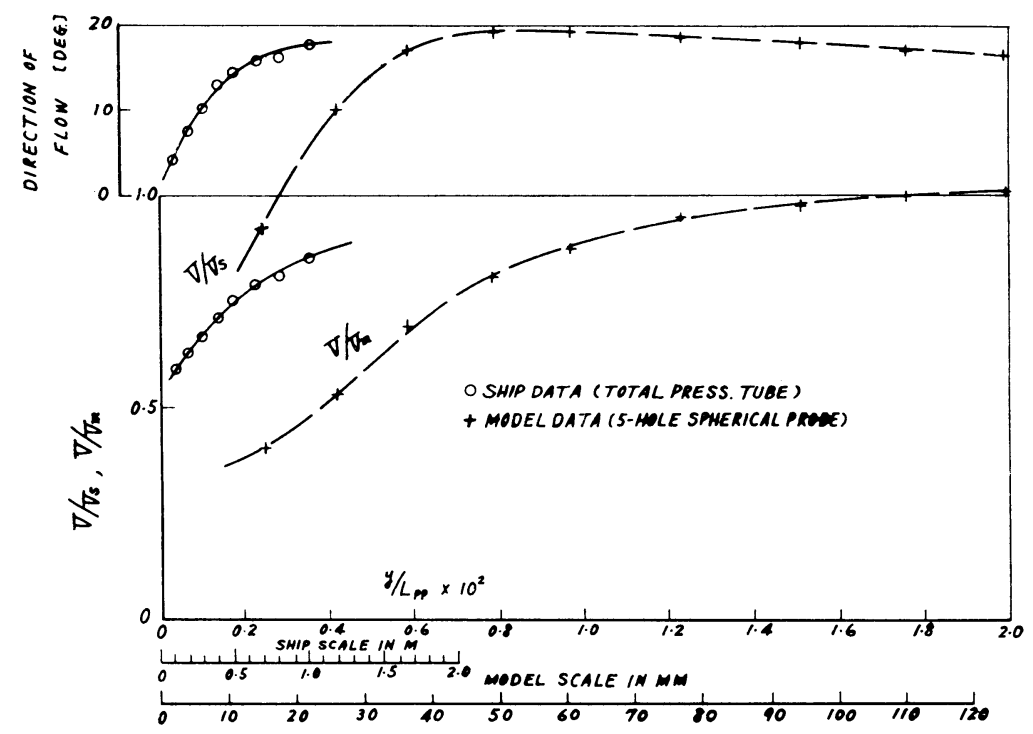

Fig. 10 Comparison of Velocity Distribution and Direction of Flow between on Ship \& Model (Ballasted Condition)

propulsion condition respectively. There is a slight difference between TR and TS conditions.

Model data of five hole spherical pitot probe on the fully loaded condition at the TR condition were corrected to the TS condition based on Fig. 11 and plotted in Fig. 9, but the model data in Fig. 10 has not been corrected. As is evident from Fig. 9, the direction of flow measured by the total pressure tube agrees well with that measured by the five hole spherical pitot probe, but $V / V m$ does not agree precisely with each other. There may be some interference between the five hole spherical pitot probe and the hull surface, but except those near surface positions the measurements by five hole spherical pitot probe may be thought more reliable. The difference between those test results may be thought due to the fact that the direction of flow is not parallel to the hull surface in

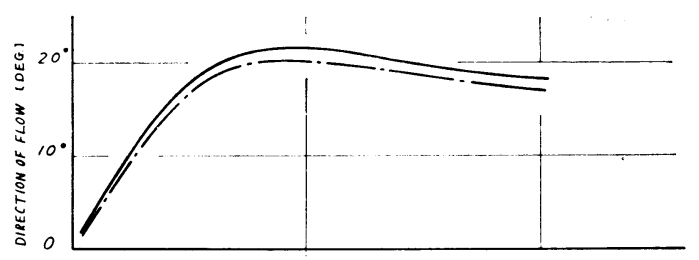
outer region of boundary layer.

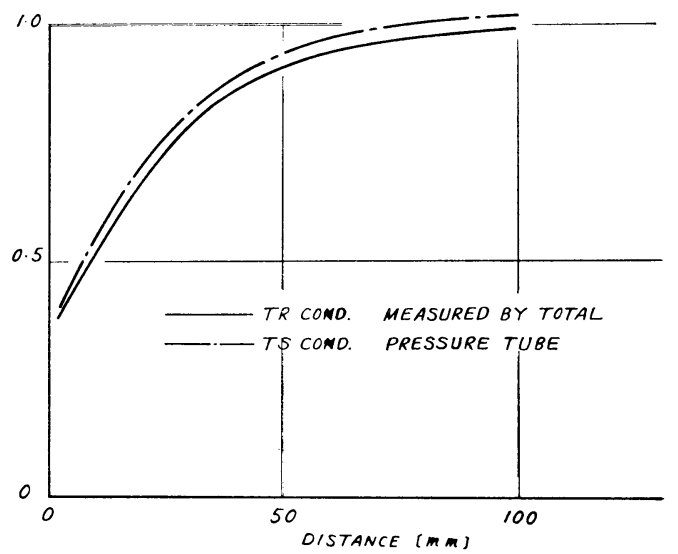

Fig. 11 Velocity Distribution and Direction of Flow in the Boundary Layer of Model (Fully Loaded Condition)

Therefore, it may be reasonable to compare the ship data with the model data measured by total pressure tube, because the ship data include the same error as mentioned above.

On the ship data, the difference of velocity distibution between the two load conditions is smaller than that of model data. The difference between the model data and ship data at the ballasted condition is larger than that of fully loaded condition. 
On the direction of flow, there can be seen a remarkable difference between ship and model data in the near surface region as shown in Figs. 9 and 10, but the difference tends to diminish in the outer region of boundary layer.

\section{2 Boundary layer thickness}

On the model tests the measuring range covers enough outside of boundary layer. In order to determine the boundary layer thickness on the model, the total pressure distribution is plotted as shown in Figs. 12 and 13. In the figure $P t / P t_{0}$ represent the proportion of total pressure loss in the boundary layer, where $P t$ is pressure difference between total pressure at the measured point and static pressure at the same level in the uniform undisturbed flow far apart from the hull, and $P t_{0}$ is the dynamic pressure in the uniform flow. $P s$ is the pressure difference between static pressure at the measured point and that of the uniform undisturbed flow at the same level. $P t / P t_{0}$ is always 1.0 in potential flow and less than 1.0 in the boundary layer in viscous flow, therefore it seems rational to determine the boundry layer thickness by means of the plotting of $P t / P t_{0}$.

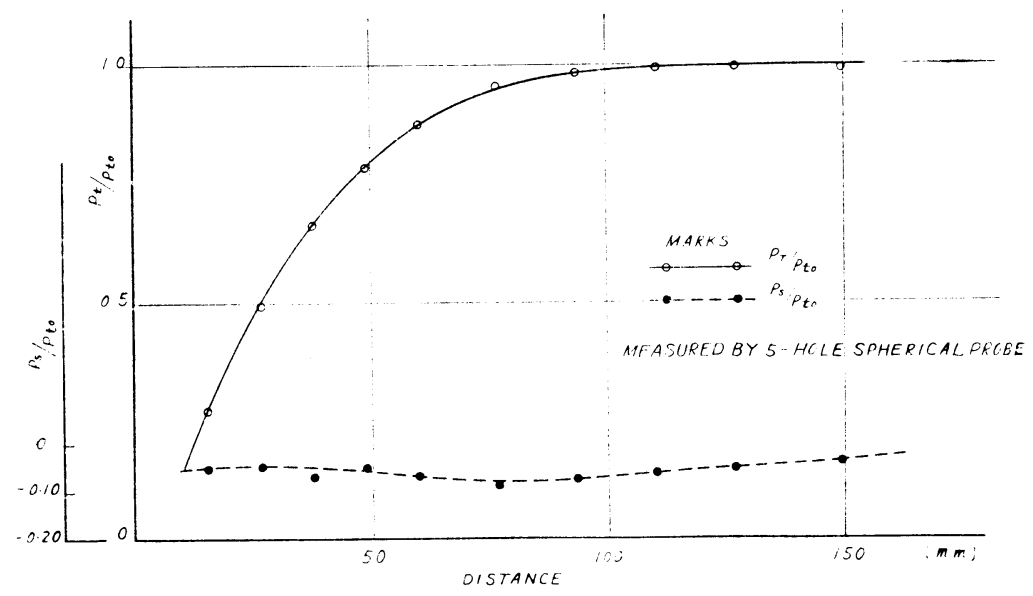

Fig 12 Pressure Distribution in the Boundary Layer of Model (Fully Loaded Condition)

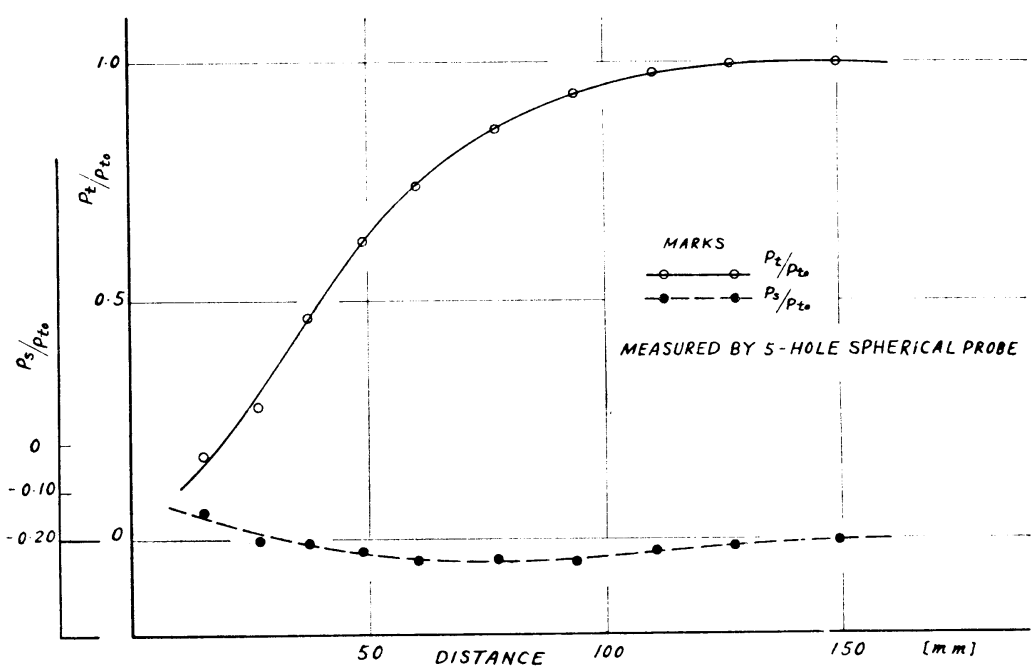

Fig. 13 Pressure Distribution in the Boundary Layer of Model (Ballasted Condition) 
From the figure, boundary layer thickness $\delta$ on the model is $110 \mathrm{~mm}$ and $135 \mathrm{~mm}$ for fully loaded and ballasted condition respectively. And the velocity of flow at the outside of boundary layer is obtained as $1.02 \mathrm{Vm}$ and $1.01 \mathrm{Vm}$ for each loaded condition.

On the ship experiment measuring range is insufficient to estimate definitely the boundary layer thickness and the velocity of flow at the outside of boundary layer. Assuming that $V / V s$ is equal to $V / V m$ at the outside of boundary layer, the boundary layer thickness can be estimated by extrapolating $V / V s$ curve. From such assumption the boundary layer thickness $\delta$ on the ship is obtained as $2.2 \mathrm{~m}$ and $2.6 \mathrm{~m}$ for fully loaded and ballasted condition respectively.

\section{3 Discussion}

From the above data the non-dimensional velocity distribution $V / V_{0} \sim y / \delta$ in the boundary layer was calculated and plotted as shown in Figs. 14 and 15. In the figure $V_{0}$ is velocity of flow at the outside of boundary layer, and velocity distribution based on the one seventh power law is shown for reference by the broken line.

From these figures, it is clear that the velocity distribution of the ship agrees approximately with the one seventh power law. On the model, especially on ballasted condition, velocity drop near the hull surface is so remarkable that the velocity distribution is quite unsimilar to that of the ship.

From the velocity distribution in these figures, displacement thickness $\delta^{*}$ and momentum thickness $\theta$, shape factor $H$ and $\eta$ are caluculated as shown in Table 1 .

They are defined by the following evuations;

$$
\begin{aligned}
\partial^{*} & =\int_{0}^{o}\left(1-\frac{V}{V_{0}}\right) d y \\
\theta & =\int_{0}^{o} \frac{V}{V_{0}}\left(1-\frac{V}{V_{0}}\right) d y \\
H & =\frac{\delta^{*}}{\theta} \\
\eta & =1-\left(\frac{V(\theta)}{V_{0}}\right)^{2},
\end{aligned}
$$

where $V(\theta)$ denotes the velocity in the boundary layer at a distance $y=\theta$ from the wall.

Table 1 Boundary Layer Thickness and Parameters

\begin{tabular}{|c|c|c|c|c|}
\hline & \multicolumn{2}{|c|}{ Model } & \multicolumn{2}{c|}{ Ship } \\
$\begin{array}{c}\text { Fully Loaded } \\
\text { Cond. }\end{array}$ & $\begin{array}{c}\text { Ballasted } \\
\text { Cond. }\end{array}$ & $\begin{array}{c}\text { Fully Loaded } \\
\text { Cond. }\end{array}$ & $\begin{array}{c}\text { Ballasted } \\
\text { Cond. }\end{array}$ \\
\hline$\delta$ & $110 \mathrm{~mm}$ & $135 \mathrm{~mm}$ & $2.2 \mathrm{~mm}$ & $2.6 \mathrm{~mm}$ \\
$\delta^{*}$ & $0.147 \delta$ & $0.161 \delta$ & $0.119 \delta$ & $0.141 \delta$ \\
$\theta$ & $0.095 \delta$ & $0.100 \delta$ & $0.090 \delta$ & $0.099 \delta$ \\
$H$ & 1.548 & 1.610 & 1.322 & 1.425 \\
$\eta$ & 0.691 & 0.848 & 0.554 & 0.564 \\
\hline
\end{tabular}

$H$ and $\eta$ are the parameters used for the

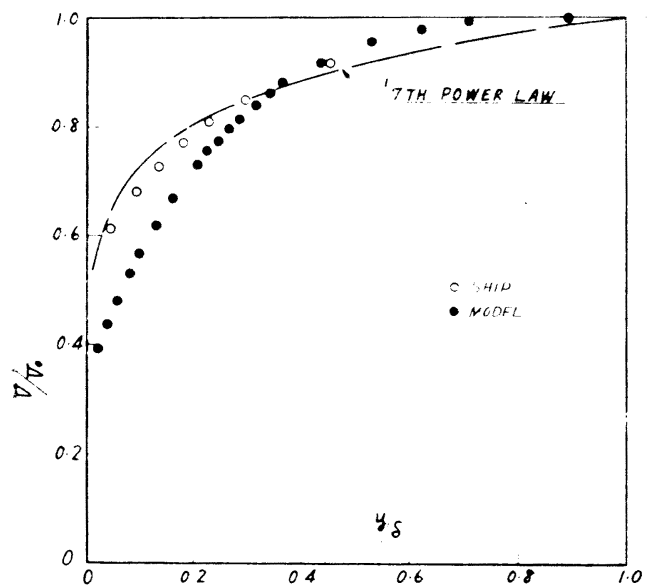

Fig. 14 Comparison of Velocity Distribution (Fully Loaded Condition)

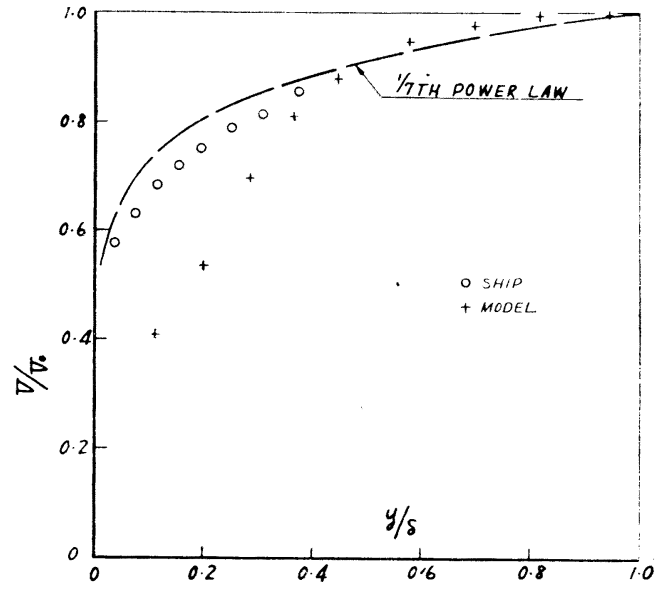

Fig. 15 Comparison of Velocity Distribution (Ballasted Condition) 
analysis of turbulent boundary layer with pressure gradient. According to Nikuradse's experiments, velocity profile with decreasing pressure corresponds to $\eta<0.45$ and those with pressure rise corresponds to $\eta>0.45$, and the seperation occurs at $\eta \approx 0.8$ or $H=1.8 \sim 2.4$.

From the table, $H$ and $\eta$ of model tests are larger than those of ship experiment and those of ballasted condition are larger than those of fully loaded condition. It is clear that the profile of velocity distribution on the model is much more affected by pressure gradient than that of the ship. Furthermore, those of ballasted condition is much more affected than those of fully loaded condition. Especially on the ballasted condition of the model the values of $\eta$ and $H$ suggest that the flow is in nearly separated condition.

From the velocity distribution we can obtain frictional (or viscous) resistance coefficient on the measured point by integrating the loss of momentum in the boundary layer, but this time the authors will not discuss this point because measured point was only one and its position seems to be unsuitable to disscuss this subject.

Variation of the direction of flow shown in Figs. 9 and 10 seem to represent the secondary flow which appears in three dimensional boundary layer.

Generally the variation of static pressure in the boundary layer is little as shown in Figs. 12 and 13 , so pressure distribution on a hull surface seems to be almost equal to that of outside the boundary layer.

As the velocity of flow near the hull surface is much smaller than outside of the boundary layer, the flow is more affected by the pressure distribution and the direction of flow is more deviated from that of main flow. Moreover if the pressure distribution is assumed to be similar at the outside of boundary layer between ship and model, the direction of flow in the boundary layer is not similar because the velocity distribution in the boundary layer is not similar to each other. As for the present test results, the discrepancy of direction of flow between ship and model seems to be mainly due to the difference of velocity distribution.

\section{Conclusions and Acknowledgement}

Measurement of velocity distribution in the boundary layer of a large tanker and her 6.25 meter model were carried out in order to contribute to the development on the correlation study of wake. From this study the following conclusions are derived.

(1) Difference in the pattern of velocity distribution in the boundary layer between fully loaded and ballasted condition is small on the ship, while it is rather large on the model.

(2) Velocity distribution in the boundry layer at the measured point on the ship agrees approximately with the $1 / 7$ th power law.

(3) Velocity distribution in the boundary layer on the model is not similar to that of ship and the velocity drop near the hull surface is more remarkable on the model.

(4) Thus the velocity distribution in the boundary layer on the model is very close to separation, while that of ship is still stable.

(5) As for the direction of flow, the difference between on the ship and the model is remarkable and this seems to be mainly due to the different velocity distribution.

At the end the authors wish to thank the staff of Machinery Laboratory and Experimental Tank of Nagasaki Technical Institute and the engineers of Nagasaki Shipyard and Engine Works for their cooperation. 


\section{References}

(1) G. Aertssen, “Sea Trials on a Victory Ship, A. P. 3, in Normal Merchant Service”, Trans. I.N.A. Vol. 95, (1953)

(2) S. Livingston Smith, "B.S.R.A. Resistance Experiments on the Lucy Ashton" Part 4, Trans. I.N.A. Vol. 97, (1955)

(3) G. Aertssen, “Sea Trials on a 9,500-ton Deadweight Motor Cargo Liner”, Trans. I.N.A. Vol. 97, (1955)

(4) T. Kumai et al, „Measurements of Boundary Layers of Ships, The First Report-Wakasugi Tests”, Reports of Research Institute for Applied Mechanics, Kyushu University No. 28 (1967)

(5) T. Kumai et al, "Measurements of Boundary Layers of Ships, The Second Report-Nansei Maru Tests”, Reports of Research Institute for Applied Mechanics, Kyushu University No. 28 (1967) 